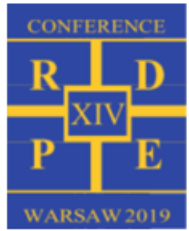

\title{
Influence of three surface condensers connection setup on power plant unit performance
}

\author{
Ewa Dobkiewicz-W ieczorek ${ }^{1, *}$ \\ ${ }^{1}$ Silesian U niversity of Technology / V almet A utomation, edobkiewicz@ wp.pl, Poland
}

\begin{abstract}
This paper presents a comparison of three surface condenser connection setups on the cooling water side. Serial, mixed and parallel connections were considered. The thermodynamic justification for the use of more complex configurations was verified. The analysis was conducted based on the calculated heat balances of verified power units for nominal and not nominal parameters for tested connections. The exhaust steam pressure was calculated using the technical data of the surface condenser and cooling water parameters. Three methods of calculating the heat transfer coefficient based on characteristic numbers, $\mathrm{HEI}$ method, and the ASME standard, were used. The most advantageous model was indicated and used in heat balance calculations. The assumptions and simplifications for the calculations are discussed. Examples of the calculation results are presented.
\end{abstract}

The direction of development and transformation in the Polish power industry are a response to the new European legal regulations, the aim of which is the environmental protection. As a result, diversification of electricity production was provoked, additionally coal-fired units were forced to apply new solutions. N ew units are getting greater, technically and technologically more advanced. Introduced improvement that increases unit efficiency by as much as 0.1 percent are important considering the actual requirements and unit efficiency of $45 \%$ net.

In the case of great unites, when few surface condensers are used, it is essential to verify, which connection setups on the cooling water side would give the highest unit efficiency.

When research, it is necessary to consider the entire steam-condensate cycle to analyze exhaust steam pressure changes effect on steam flow and thermodynamic parameters fluctuations. The correct calculation of the exhausted steam pressure value is one of key steps to ensure the calculation's correctness. This paper presents analysis of three exhausted steam pressure calculation algorithms, comparison of their complexity and the set of the data needed for these calculations. The model of the surface condenser was based on three methods of calculating the heat transfer coefficient: dimensionless equation with characteristic numbers, the HEI method and the ASME standard. The most advantageous model was indicated after verification with the data from the site.

Study of three surface condenser connection setups on the cooling water side aims to help to find the answer on the rationale behind using more complex configurations, to analyze their advantages and disadvantages, and to give advice on which system is the best from the thermodynamics perspective.

\section{Exhaust steam pressure calculation}

Condensation turbine exhaust steam pressure was calculated using the heat transfer equations.

M odel assumed isobaric heat exchange, no condensate subcooling. Calculations were made for steady state. Thermodynamic calculations in accordance with IA PWS IF-97 [1].

\subsection{Heat transfer equations:}

Heat transfer equations are:

$$
\begin{aligned}
& \dot{Q}=\dot{m}_{s}\left(i_{s}-i_{c}\right) \\
& \dot{Q}=\dot{m}_{g} C p_{g}\left(T_{2}-T_{1}\right) \frac{1}{\eta_{c}}
\end{aligned}
$$

Nomenclature: $\dot{Q}$ - heat transfer rate, $\dot{m}_{s}$ - exhausted steam flow rate, $i_{s}-$ exhausted steam enthalpy, $i_{c}$ - condensate enthalpy, $\dot{m}_{g}$ - cooling water flow rate, $C p_{g}$ - water specific heat, $T_{1}$ - inlet cooling water temperature, $T_{2}$ - outlet cooling water temperature, $\eta_{c}-$ condenser efficiency

\subsection{Condenser heat load: [2],[4],[5].}

Condenser heat load equation is:

$$
\begin{aligned}
& \dot{Q}=U A_{s} L M T D \\
& L M T D=\frac{T_{2}-T_{1}}{l \frac{T_{T}-T_{1}}{T_{S}-T_{2}}}
\end{aligned}
$$

Nomenclature: $\dot{Q}$ - condenser heat load, U - heat transfer coefficient, $A_{S}$ - surface tube area, LMTD - logarithmic mean temperature difference, $\mathrm{T}_{\mathrm{c}}-$ condensate temperature, $\mathrm{T}_{\mathrm{S}}-$ steam temperature, $T_{1}$ - inlet cooling water temperature, $T_{2}$ - outlet cooling water temperature. 


\subsection{Heat transfer coefficient - Characteristic numbers [2].}

Heat transfer coefficient, when characteristic number method used, equation is:

$$
U=\frac{1}{R_{m}+R_{t} \frac{D_{\text {out }}}{D_{i}}+R_{S}+R_{f}} 10^{-3}
$$

Tube-W all resistance was computed as follows:

$$
R_{m}=D_{\text {out }} \ln \frac{D_{\text {out }}}{D_{i}} \frac{1}{2 K_{m}}
$$

Shellside resistance was computed based on dimensionless equation for heat transfer when the steam condenses on the outside horizontal pipe's surface.

$$
\begin{aligned}
& R_{s}=\left(\frac{N u K_{s}}{D_{\text {out }}}\right)^{-1} \\
& N u=0.725 C_{v}{ }^{0.25} \\
& C_{v}=\frac{D_{o u t}{ }^{3} \delta_{c}^{2} g d i_{v a p}{ }^{2}}{K_{t} \mu_{c} d T_{c t}}
\end{aligned}
$$

$d T_{c t}$ - The difference in condensate and wall temperatures depends on the thickness of the condensate layer, therefore on the heat transfer coefficient. It is indicating that the most appropriate calculation method is the iterative method, but with satisfactory accuracy, the value can be calculated as $d T_{c t}=\frac{L M T D}{2}$ [3].

Physical properties of condensate: $\delta_{c}, K_{t}, \mu_{c}$ are determined for surface and saturation average temperature $T_{f}=\frac{T_{s}+\left(T_{S}+d T_{c t}\right)}{2}$

Tubeside resistance was computed based on dimensionless equation for forced convection for turbulent flow inside a circular pipe:

$$
\begin{gathered}
R_{t}=\left(\frac{N u K_{t}}{D_{i}}\right)^{-1} \\
N u=0.021 R e^{0.8} \mathrm{Pr}_{g}{ }^{0.43}\left(\frac{P r_{g}}{P r_{t}}\right)^{0.25} \\
\operatorname{Re}=\frac{V_{g} D_{i} \delta_{g}}{\mu_{g}} \\
V_{g}=\frac{W_{g}}{\delta_{g}} \frac{4}{N \pi D_{i}{ }^{2}} \\
\operatorname{Pr}=\frac{\mu C p}{K}
\end{gathered}
$$

$P r_{g} / P r_{t}$ - calculated for water temperature $T_{g}$ and wall temperature $T_{t}=T_{s}-d T_{c t}$

Nomenclature: $U-$ heat transfer coefficient, $D_{i}-$ tube inside diameter, $D_{\text {out }^{-}}$tube outside diameter, $K_{m}$-tubewall resistance, $K_{t^{-}}$tubeside thermal conductivity, $K_{s^{-}}$shellside thermal conductivity, $R_{m}{ }^{-}$tubewall resistance, $R_{t^{-}}$tubeside resistance, $R_{s^{-}}$shellside resistance, $R_{f^{-}}$fouling resistance, $\mathrm{Nu}$ - N uselt number, $\mathrm{Pr}$ - Prandl number, $\mathrm{Re}-$ Reynolds number, $T_{g^{-}}$average cooling water temperature, $V_{g}$ - cooling water velocity, $\mathrm{Cp}_{g}-$ water specific heat, $d i_{\text {vap }}{ }^{-}$enthalpy of exhausted steam vaporization, $d T_{c t^{-}}$. The difference in condensate and wall temperatures, $\mu_{c}$ - condensate viscosity, $\mu_{g}$ - cooling water viscosity, $\delta_{g^{-}}$cooling water density, $\delta_{c}-$ condensate density

\subsection{Heat transfer coefficient - HEl standard [4]}

In this case, the calculation of heat transfer coefficient is based on design guidelines of $\mathrm{Heat}$ Exchange Institute (HEI). The proposed function uses the data from experimental research. The heat transfer coefficient was computed as follows

$$
U=U_{1} F_{w} F_{m} F_{c}
$$

Nomenclature: $U_{1}-$ uncorrected heat transfer coefficients, as a function of tube diameter and cooling water velocity, $F_{w}$-inlet water temperature correction factor, $F_{m}$ - tube material and gauge correction factors, $F_{c}$ - cleanliness factor.

$U_{1}, F_{w}, F_{m}$ are read from $\mathrm{HEI}$ table. $U_{1}$ values are based on clean, $1.245 \mathrm{~mm}$ tube wall gauge, Admiralty metal tubes with $21.1^{\circ} \mathrm{C}$ cooling water temperature. Uncorrected heat transfer coefficient is describing as a function of tube diameter and water velocity. $F_{w}$ introduces a water temperature correction and $F_{m}$ introduces a tube material and gauge correction.

\subsection{Heat transfer coefficient - ASME PTC 12.2 codes: [5]}

Heat transfer coefficient, when ASME codes used, equation is:

$$
U=\frac{1}{R_{m}+R_{t} \frac{D_{\text {out }}}{D_{i}}+R_{S}+R_{f}} 10^{-3}
$$

Tube-Wall resistance was computed as follows:

$$
R_{m}=D_{\text {out }} \ln \frac{D_{\text {out }}}{D_{i}} \frac{1}{2 K_{m}}
$$

Tubeside resistance was computed as follows:

$$
\begin{aligned}
& R_{t}=\left(\frac{N u K_{t}}{D_{i}}\right)^{-1} \\
& N u=0.0158 \operatorname{Re}^{0.835} \mathrm{Pr}^{0.426} \\
& \operatorname{Re}=\frac{V_{g} D_{i} \delta_{g}}{\mu_{g}} \\
& V_{g}=\frac{W_{g}}{\delta_{g}} \frac{4}{N \pi D_{i}^{2}} \\
& \operatorname{Pr}=\frac{\mu C P}{K}
\end{aligned}
$$

Shellside resistance for the first iteration was computed as follows:

$$
R_{s}=\frac{1}{U 10^{3}}-R_{m}-R_{t} \frac{D_{\text {out }}}{D_{i}}-R_{f}
$$

Shellside resistance for the next iteration was computed as follows:

$$
R_{S}=R_{S 0}\left(\frac{\dot{Q}_{0}}{\dot{Q}}\right)^{\frac{1}{3}}\left(\frac{\mu_{0}}{\mu}\right)^{\frac{1}{3}} \frac{K_{S 0}}{K_{S}}\left(\frac{\delta_{0}}{\delta}\right)^{\frac{2}{3}}
$$

Nomenclature determined as in point 1.3.

Index 0 means the value from the previous iteration. Physical properties of condensate: $\delta, K, \mu$ are determined for condensate film $T_{f}=T_{s}-0.2 L M T D$.

Condenser technical data: Steel 1.4401 $K_{m}=15 \frac{\mathrm{W}}{\mathrm{mK}}$ was assumed to be used, tube dimension $\varnothing 24 \times 0.7 \mathrm{~mm}$, condenser efficiency $\eta_{c}=0.99$, cleanliness factor $\mathrm{k} F_{c}=0.95$; Calculation was done for two pass surface condenser with surface tube area $A_{s}=19177 \mathrm{~m}^{2}$, quantity of tubes $N=31920$.

\subsection{Turbine's isentropic efficiency}

In calculation turbine's isentropic efficiency was used

$$
\eta_{1}=\frac{i_{S L L P}-i_{S}}{i_{S L L P}-i_{S 0}}
$$

Nomenclature: $i_{S_{-} L P}-$ inlet LP turbine steam enthalpy, $i_{s}$ - exhaust steam enthal py, $i_{s 0}-$ exhaust steam enthal py when isentropic flow, $p_{s}$ - exhaust steam pressure, 
$\eta_{1}$ was set as a constant because in external test, small impact of vary this value as a function of load, for main calculation, was verified.

\subsection{Calculation procedure and example calculation results}

Variables calculation was based on the iterative algorithm. Calculation procedure is the same for dimensionless equation with characteristic number ( $\mathrm{CN}$ ) and $\mathrm{HEI}$ methods but different for ASM E standard.

Input data: $A_{s}$ - surface tube area, $N$ - quantity of tubes, $F_{c}$ - cleanliness factor, $D_{i}-$ tube inside diameter, $D_{\text {out }}{ }^{-}$tube outside diameter, $K_{m}$ - tubewall thermal conductivity, $\dot{m}_{g}$ - cooling water flow rate, $p_{g}$ - cooling water pressure, $T_{1}-$ inlet cooling water temperature, $p_{S_{-} L P}-$ inlet LP turbine steam pressure, $T_{S_{-} L P}-$ inlet LP turbine steam temperature, $\dot{m}_{s}-$ exhausted steam flow rate, $d T_{c}$-condensate subcooling, $\eta_{1}$ - turbine efficiency, $\eta_{c}$-condenser efficiency, condenser pass number

\section{Calculation procedure}

\section{$\mathrm{CN}, \mathrm{HEI}$ method}

- Initialization parameters $\dot{Q}, U$

Calculation

- $T_{2}$ based on (2)

- LMTD based on (3)

- $T_{s}$ based on (4)

- $p_{s}=f\left(p_{-} \operatorname{sat}\left(T_{s}\right)\right)$,

$i_{S_{-} L P}=f\left(p_{S_{-} L P}, T_{S_{-} L P}\right)$

- $i_{s}$ based on (8)

- $x_{s}=f\left(p_{s}, i_{s}\right)$

- $\dot{Q}$ based on (1)

- $U$ based on (5) / (6)

Next iteration
ASME method Initialization

parameters $p_{s}$ Calculation

- $T_{s}=f\left(T_{-} s a t\left(p_{s}\right)\right)$,

$i_{S_{-} L P}=f\left(p_{s_{-} L P}, T_{S_{-} L P}\right)$

- $i_{s}$ based on (8)

- $x_{s}=f\left(p_{s}, i_{s}\right)$

- $\dot{Q}$ based on (1)

- $T_{2}$ based on (2)

- LMTD based on (4)

- $U$ based on (3)/ (7)

- LMTD based on (3)

- $T_{s}$ based on (4)

- $p_{s}=f\left(p \_s a t\left(T_{s}\right)\right)$

$\mathrm{N}$ ext iteration
In table 1 input data were presented. In table 2 example calculation results compare with real exhausted steam pressure were shown.

\subsection{Discussion of the results and exhaust steam pressure calculation method selection.}

$\checkmark$ erifying calculations have been made for data from real units: $65 \mathrm{M} \mathrm{W}$ and $460 \mathrm{M} \mathrm{W}$. This paper presents results for

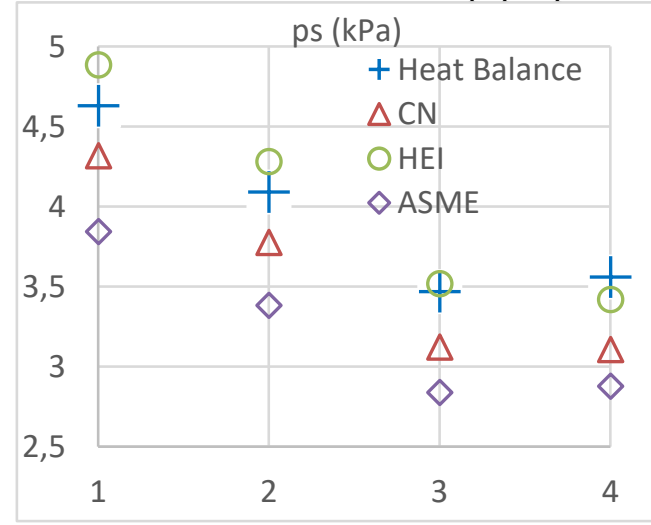

Fig. 1. Exhausted steam pressure
Table 1. Input data for calculations

\begin{tabular}{|c|c|l|l|l|l|}
\hline \multicolumn{2}{|l|}{ series } & 1 & 2 & 3 & 4 \\
\hline load & & $100 \%$ & $90 \%$ & $75 \%$ & $60 \%$ \\
\hline$\dot{m}_{g}$ & $\frac{t}{h}$ & 48060 & 48060 & 48060 & 48060 \\
\hline$T_{1}$ & ${ }^{\circ} \mathrm{C}$ & 18.3 & 16.8 & 15.2 & 16.7 \\
\hline$\dot{m}_{s}$ & $\frac{k g}{h}$ & 753240 & 697910 & 587350 & 491770 \\
\hline$T_{s_{-} L P}$ & ${ }^{\circ} \mathrm{C}$ & 278.7 & 273.6 & 280 & 272.6 \\
\hline$p_{S_{-} L P}$ & $k P a$ & 579 & 526 & 441 & 358 \\
\hline$\eta_{1}$ & & 0.82 & 0.82 & 0.82 & 0.82 \\
\hline
\end{tabular}

Nomenclature: $\dot{m}_{g}-$ cooling water flow rate; $T_{1}$ - inlet cooling water temperature; $\dot{m}_{s}$ - exhausted steam flow rate; $T_{S_{-} L P}-$ inlet LP turbine steam temperature; $p_{S_{-} L P}-$ inlet LP turbine steam pressure, $\eta_{1}-$ LP turbine's isentropic efficiency

Table 2. Example calculation results

\begin{tabular}{|c|c|c|c|c|c|}
\hline \multicolumn{2}{|l|}{ series } & 1 & 2 & 3 & 4 \\
\hline \multicolumn{2}{|l|}{ load } & $100 \%$ & $90 \%$ & $75 \%$ & $60 \%$ \\
\hline$p_{S_{-} R E F}$ & $k P a$ & 4.63 & 4.09 & 3.47 & 3.56 \\
\hline \multicolumn{6}{|c|}{$\mathrm{CN}$} \\
\hline$p_{s}$ & $k P a$ & 4.31 & 3.77 & 3.12 & 3.10 \\
\hline$\dot{Q}$ & $k W$ & 466641 & 432688 & 368136 & 310295 \\
\hline$U$ & $\frac{k W}{m^{2} K}$ & 3.45 & 3.41 & 3.38 & 3.45 \\
\hline$T_{2}$ & ${ }^{\circ} \mathrm{C}$ & 26.6 & 24.5 & 21.7 & 22.2 \\
\hline \multicolumn{6}{|c|}{$\mathrm{HEI}$} \\
\hline$p_{s}$ & $k P a$ & 4.88 & 4.28 & 3.51 & 3.41 \\
\hline$\dot{Q}$ & $k W$ & 467298 & 433316 & 368667 & 310664 \\
\hline$U$ & $\frac{k W}{m^{2} K}$ & 2.59 & 2.52 & 2.45 & 2.52 \\
\hline$T_{2}$ & ${ }^{\circ} \mathrm{C}$ & 26.6 & 24.5 & 21.7 & 22.2 \\
\hline \multicolumn{6}{|c|}{ ASME } \\
\hline$p_{s}$ & $k P a$ & 3.84 & 3.38 & 2.83 & 2.87 \\
\hline$\dot{Q}$ & $k W$ & 466023 & 432138 & 367714 & 310000 \\
\hline$U$ & $\frac{k W}{m^{2} K}$ & 5.19 & 5.11 & 5.02 & 5.06 \\
\hline$T_{2}$ & ${ }^{\circ} \mathrm{C}$ & 26.6 & 24.5 & 21.7 & 22.2 \\
\hline
\end{tabular}

Nomenclature: $p_{S_{-} R E F^{-}}$reference exhausted steam, $p_{s^{-}}$ calculated exhausted steam, $\dot{Q}$ - condenser heat load, $U$ heat transfer coefficient, $T_{2}$ - outlet cooling water temperature

the bigger one. Figure 1 presents calculated exhausted steam pressure compared with reference value. The most similar results to the expected value gave $\mathrm{HEI}$ method al though results of characteristic numbers method are also correct. The square root error of exhaust steam pressure 
was used to assess the series of results. For calculation based on $\mathrm{HEI}$ method it is $0.176 \mathrm{kPa}$, for characteristic numbers method $0.361 \mathrm{kPa}$, for A SM E method $0.704 \mathrm{kPa}$. For second reference unite the best results gave characteristic numbers and $\mathrm{HEI}$ method. Least accurate results give A SME method. Although this method largely based on similar equations as characteristic numbers method, significant results difference follows on from shellside resistance calculation. Reviewing the actual reference data, it is concluded that the results with the best accuracy were obtained using the HEI method. It is also the simplest method when considering the complexity of the calculations.

\section{Comparison of three surface condenser connection setups on the cooling water side.}

Four condenser connection configurations were tested: I- parallel (Fig.2), II-serial (Fig.3), III- parallel-to-serial (Fig.4) and IV - serial-to-parallel (Fig.5). For proposed thermal cycle (Fig.6) nominal load heat balance was calculated. Next heat balance for $70 \%$ and $40 \%$ of nominal load was computed. Considering steam flow change and thermodynamic parameters fluctuations, the influence of the tested connections on improving the unit efficiency was verified.

\subsection{Calculation procedure [6]}

The unit shown as a Figure 6 was described by energy and mass balances equations. The coefficients of the system of equations were appointed by the enthal py value at the determined points. Enthalpy was calculated from the thermodynamics dependence in accordance with IAPW S IF-97. Exhausted steam pressure was calculating based on algorithm with $\mathrm{HEI}$ heat transfer coefficient. By iterating these three calculation steps, the pressure, temperature, enthalpy and mass flow were computed for the determined points at nominal load.

Calculations input data were: $p_{0}$ - live steam pressure, $t_{0}$ - live steam temperature, $t_{20}$ - reheated steam temperature, $N_{e l}$ - electric power and value needed to exhausted steam pressure calculation presented in first part of this thesis.
Using Stodola-Flügel turbine passage equation calculation for $70 \%$ and $40 \%$ of nominal load were done. Calculations input data were: $t_{0}, t_{20}, N_{e l}$ and value needed to exhausted steam pressure calculation.

To compare the results operation following indicators were calculated: gross unit heat rate and unit efficiency.

$$
\begin{array}{r}
q=3600 \frac{\dot{Q}_{d}}{N_{e l}}\left[\frac{k J}{k W h}\right] \\
\eta=\frac{N_{e l}}{\dot{Q}_{d}}
\end{array}
$$

Where $\dot{Q}_{d}=m_{0}\left(i_{0}-i_{100}\right)+m_{19}\left(i_{20}-i_{19}\right)$

Comparing the proposed configurations, the following assumptions were made: equal steam distribution to the

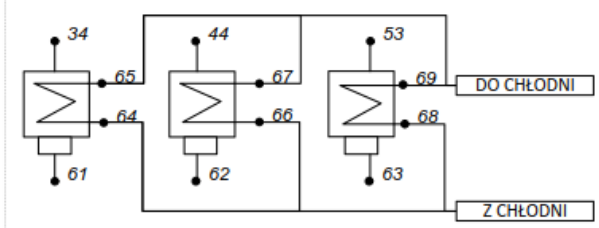

Fig. 2. Parallel configuration

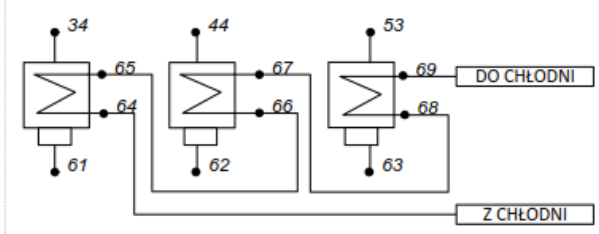

Fig. 3. Serial configuration

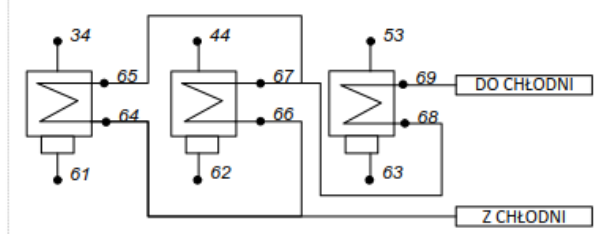

Fig. 4. Parallel-to-serial configuration

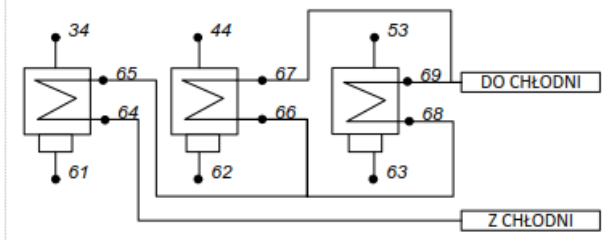

Fig.5. Serial-to-parallel configuration

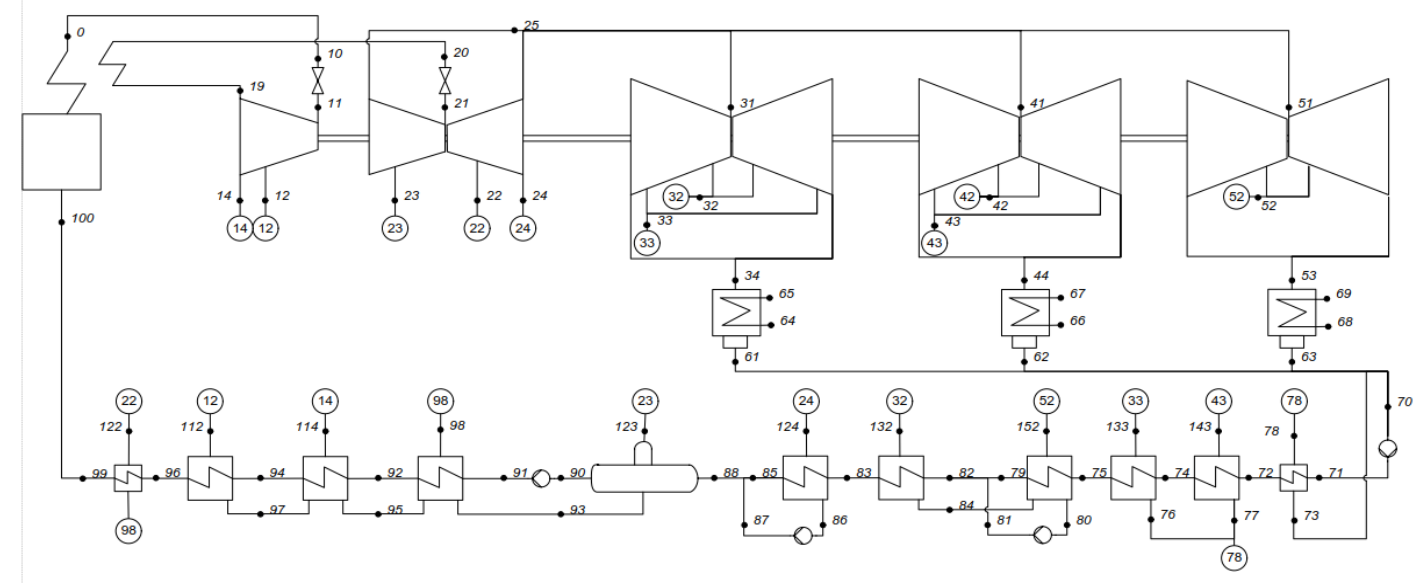

Fig.6. Tested thermal cycle scheme 
LP turbine part, the total surface tube in each configuration is similar, the amount of cooling water is the same and the number of tubes has been chosen so that the cooling water velocity does not exceed $2.6 \frac{\mathrm{m}}{\mathrm{s}}$.

It was assumed: one pass surface condenser except the parallel configuration where two pass surface condenser was selected; use of steel $1.4401-K_{m}=15 \frac{\mathrm{W}}{\mathrm{mK}}$, tube dimension $\varnothing 22 \times 0.5 \mathrm{~mm}$, condenser efficiency $\eta_{c}=$ 0.99 , cleanliness factor $F_{c}=0.95$;

In table 3.1 and 3.2 input data for the calculations were presented. Following, proposed configurations were compared after changing parameters: temperature or flow of cooling water, heat exchange surface, temperature of live and reheated steam, cleanliness factor

Tabela 3.1 Input data for the calculations (the same for all configuration)

\begin{tabular}{|c|c|l|c|c|l|}
\hline$p_{0}$ & $M P a$ & 28.5 & $A_{s}$ & $m^{2}$ & $\sim 48700$ \\
\hline$t_{0}$ & ${ }^{\circ} \mathrm{C}$ & 600 & $\dot{m}_{g}$ & $\frac{t}{h}$ & 81000 \\
\hline$t_{20}$ & ${ }^{\circ} \mathrm{C}$ & $610 / 600 *$ & $\eta_{1}$ & - & 0.89 \\
\hline$T_{1}$ & ${ }^{\circ} \mathrm{C}$ & 16.0 & \multicolumn{3}{|l}{} \\
\cline { 1 - 3 } & & &
\end{tabular}

Tabela 3.2. Input data for the calculations (different for each configuration)

\begin{tabular}{|c|l|l|l|l|l|}
\hline \multicolumn{2}{|c|}{ configuration } & I** & II** & III** & IV** \\
\hline$A_{s 1}$ & $m^{2}$ & 16252 & 16242 & 13935 & 20903 \\
\hline$A_{s 2}$ & $m^{2}$ & 16252 & 16242 & 13935 & 13935 \\
\hline$A_{s 3}$ & $m^{2}$ & 16252 & 16242 & 20903 & 13935 \\
\hline$N_{1}$ & & 19640 & 25000 & 16840 & 25260 \\
\hline$N_{2}$ & & 19640 & 25000 & 16840 & 16840 \\
\hline$N_{3}$ & & 19640 & 25000 & 25260 & 16840 \\
\hline
\end{tabular}

*) Temperature for $40 \%$ load

**) Proposed configuration: I-parallel, II-serial, III- parallel-to-serial and $I V$-serial-to-parallel

Nomenclature: $p_{0}$ - live steam pressure, $t_{0}$-live steam temperature, $t_{20}$-reheated steam temperature, $\dot{m}_{g}$ - cooling water flow rate, $T_{1}-$ inlet cooling water temperature, $A_{s}$ - surface tube area $N$ - quantity of tubes $\eta_{1}-$ LP turbine's isentropic efficiency

\subsection{Result discusion}

The results of calculations for $100 \%$ and $40 \%$ loads are presented in tables 4.1-4.2. Figures 7.1-7.2 show the gross unit heat rate for the nominal load when the value of cooling water flow (7.1) and surface tube area (7.2) was changed. The results were compared with the results from the initial calculations (marked by $x$ ).

The best results in thermodynamic terms were obtained for a serial connection. In this case efficiency was improved by $0.15 \%$ compared to the parallel connection for nominal load and $0.1 \%$ for minimum load. Series-parallel connection was also somewhat more favorable, while other configurations are least beneficial.

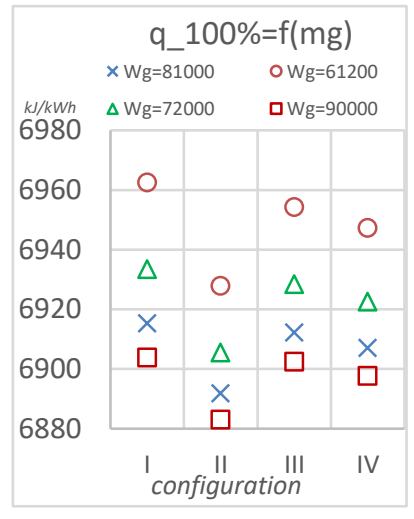

Fig. 7.1. Gross unit heat rate tested configuration when $\dot{m}_{g}$ change for nominal load

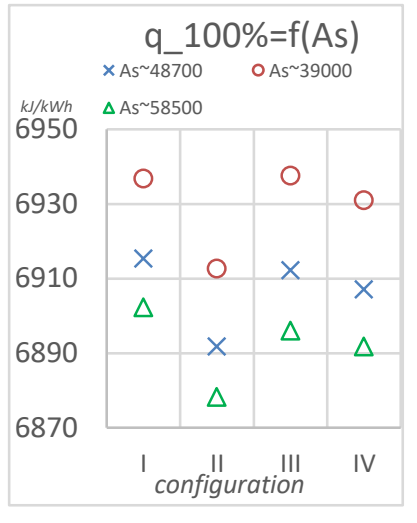

Fig. 7.2. Gross unit heat rate tested configuration when $A_{\mathrm{s}}$ $\dot{m}_{g}$ change for nominal load
Figures 7.1-7.2 show the impact of changing the relevant parameters on the gross unit heat rate $q$. On the one hand, the results show that regardless of the tested parameter, the serial system is the most advantageous. On the other hand, the charts show the savings this configuration gives. For example, a similar indicator $q$ for $72000 \frac{t}{h}$ cooling water flow for serial configuration was obtained for $90000 \frac{t}{h}$ using a parallel configuration (Fig.7.1). This gives a $20 \%$ reduction in the amount of cooling water. Figure 7.2 shows that the same indicator $q$ as for the base data series in parallel configuration can be obtained by reducing the surface tube area by $20 \%$ for the serial configuration - this can be interpreted as a decreasing surface tube area during operation. Similar conclusions were reached when analyzing subsequent results for the previously described parameters changes.

Table 4.1. Calculations results for nominal load

\begin{tabular}{|c|c|c|c|c|c|c|c|c|}
\hline configuration & \multicolumn{2}{|c|}{ I-parallel } & \multicolumn{2}{c|}{ II-serial } & \multicolumn{2}{c|}{ III-parallel-to-serial } & \multicolumn{2}{c|}{ IV-serial-to-parallel } \\
\hline & $m$ & $p$ & $m$ & $p$ & $m$ & $p$ & $m$ & $p$ \\
\hline$i$ & $\frac{k g}{h}$ & $M P a$ & $\frac{k g}{h}$ & $M P a$ & $\frac{k g}{h}$ & $M P a$ & $\frac{k g}{h}$ & $M P a$ \\
\hline 0 & 2416392 & 28.50 & 2393172 & 28.50 & 2413044 & 28.50 & 2406960 & 28.50 \\
\hline 34 & 496260 & 0.00384 & 492192 & 0.00291 & 495648 & 0.00368 & 494604 & 0.00270 \\
\hline 44 & 482724 & 0.00376 & 478836 & 0.00341 & 482148 & 0.00362 & 481176 & 0.00424 \\
\hline 53 & 432900 & 0.00350 & 429552 & 0.00386 & 432432 & 0.00366 & 431568 & 0.00398 \\
\hline 100 & 2416392 & 32.41 & 2393172 & 32.41 & 2413044 & 32.41 & 2406960 & 32.41 \\
\hline \multicolumn{8}{|c|}{ Operation indicators } \\
\hline$q$ & 6915 & 6892 & 6912 & 6907 & \\
\hline$\eta$ & 0.521 & 0.522 & 0.521 & 0.521 & \\
\hline
\end{tabular}


Table 4.2. Calculations results for $40 \%$ of nominal load

\begin{tabular}{|c|c|c|c|c|c|c|c|c|}
\hline configuration & \multicolumn{2}{|c|}{ I-parallel } & \multicolumn{2}{|c|}{ II-serial } & \multicolumn{2}{|c|}{ III-parallel-to-serial } & \multicolumn{2}{|c|}{ IV-serial-to-parallel } \\
\hline & $\mathrm{m}$ & $\mathrm{p}$ & $\mathrm{m}$ & $p$ & $\mathrm{~m}$ & $\mathrm{p}$ & $\mathrm{m}$ & $p$ \\
\hline i & $\frac{\mathrm{kg}}{\mathrm{h}}$ & $\mathrm{MPa}$ & $\frac{\mathrm{kg}}{\mathrm{h}}$ & $\mathrm{MPa}$ & $\frac{\mathrm{kg}}{\mathrm{h}}$ & $\mathrm{MPa}$ & $\frac{\mathrm{kg}}{\mathrm{h}}$ & $M P a$ \\
\hline 0 & 910116 & 10.82 & 903996 & 10.85 & 909288 & 10.82 & 907560 & 10.83 \\
\hline 34 & 222300 & 0.00260 & 221796 & 0.00228 & 222264 & 0.00255 & 222120 & 0.00220 \\
\hline 44 & 205992 & 0.00254 & 204624 & 0.00244 & 205848 & 0.00249 & 205452 & 0.00271 \\
\hline 53 & 184248 & 0.00245 & 183024 & 0.00259 & 184068 & 0.00252 & 183744 & 0.00262 \\
\hline 100 & 910116 & 12.31 & 903996 & 12.34 & 909288 & 12.31 & 907560 & 12.32 \\
\hline \multicolumn{9}{|c|}{ Operation indicators } \\
\hline$q$ & \multicolumn{2}{|c|}{7433} & \multicolumn{2}{|c|}{7416} & \multicolumn{2}{|c|}{7431} & \multicolumn{2}{|c|}{7427} \\
\hline$\eta$ & \multicolumn{2}{|c|}{0.484} & \multicolumn{2}{|c|}{0.485} & \multicolumn{2}{|c|}{0.484} & \multicolumn{2}{|c|}{0.485} \\
\hline
\end{tabular}

\section{Conclusions}

This paper presents calculation and verification of which connection setups of surface condensers on the cooling water side is the best from thermodynamics perspective. The study was not easy, because the phenomena occurring in the last stage of the turbine and in the condenser are complex and difficult to describe using mathematical formulas. Therefore, in the first part of work, the focus was on describing and choosing the best method for calculating the exhausted steam pressure of condensing turbine. Three calculation methods were compared, results were verified with data from the factual site. Considering the correctness of the results and the complexity of the calculations, the method based on HEI standard has been identified as the most advantageous method for calculating the turbine exhaust steam pressure. It needs to be highlighted that using this method to calculate heat transfer coefficient requires only the cooling water and condenser technical parameters. There is no need to enter the parameters of exhausted steam what simplifies the calculation.

In the next step, four condenser connection configurations were tested. In each case, the serial configuration was the most thermodynamically favourable. For nominal parameters, obtained improvement of unit efficiency was around $0.15 \%$. The use of this configuration can improve unit efficiency or reduce design or operating costs by reducing surface tube area, cooling water quantity, superheated steam temperature.

However, for a serial connection, the problem of unequal operation of the LP turbine part attention should be paid to. The design of each parts of the turbine is the same, but when serial configuration is used, the exhausted steam pressure of each part is different, so they do not work at their optimal point. This is a significant problem when assuming the work of the unit mainly with nominal parameters. When serial connection is used, there is al so a large dependence of the steam parameters of next LP turbine parts, which is not present for a parallel system. Incorrect assumptions or design calculations may have a greater impact to the operation then in parallel configuration. When choosing a series system, attention should also be paid to the useful power of the condensate pump, which will certainly be higher due to the greater drop in water pressure due to the flow in the tubes.

Summarizing the researches, it has been proven that the most advantageous configuration for thermodynamic reasons is the serial configuration. Although this setup has several important disadvantages that can have a significant impact on the final result.

\section{References}

1. The International Association for the Properties of Water and Steam, Revised Release on the IAPWS Industrial Formulation 1997 for the Thermodynamic Properties of Water and Steam

2. Kostowski E.: Przepływ Ciepła, (2006)

3. Szlachtin P.N.: Turbiny Parowe, (1953)

4. HEI Standards for Steam Surface, (2012)

5. ASME PTC 12.2-2010 Steam Surface Condensers Performance Test Codes, (2007)

6. Łukowicz H.: Podstawy siłowni cieplnych, Wykłady 